\title{
Development of Menu Planning Resources for Child Care Centres: A Collaborative Approach
}

\author{
By: Linda Mann, Dana Power, and Vanessa MacLellan
}

\begin{abstract}
Linda Mann is a professional dietitian with a master's in business administration. She is an associate professor at Mount Saint Vincent University in the department of applied human nutrition. Her current research interests are the application of child care centre food and nutrition policies, influences on university student eating behaviours, and food service systems. Email: linda. mann@msvu.ca

Dana Power is a professional dietitian with a master's in education. She is the general manager of Caritas Residence for Shannex Nova Scotia. Her professional practice interests are healthy lifestyle policy development and implementation.

Vanessa MacLellan graduated in 2012 from Mount Saint Vincent University with a bachelor of science in applied human nutrition (honours). Her contribution to this study began while she was a dietetic intern and research assistant. She is now a professional dietitian.
\end{abstract}

Well-designed menus in child care centres include nutritious meals and snacks necessary for the optimum health, growth, and lifelong healthy eating behaviours of young children. With pending government food and nutrition standards, a need was identified for comprehensive, relevant, user-friendly menu planning resources. Therefore, guided by an action research model, this study identified current menu planning practices, determined the needs and expectations for menu planning resources, and developed menu planning resources that incorporate these standards and other relevant factors. Menu planners from regulated child care centres in Nova Scotia $(\mathrm{n}=330)$ were invited to participate by responding to an online survey and/or volunteering as a member of a collaboration group. Survey respondents $(\mathrm{n}=83)$ indicated that they wanted their menus to be more interesting, practical, and cost effective. Menu templates, sample menus, and costed recipes were the most requested resources. Two-thirds indicated a preference for webbased resources and about one-third expressed interest in an interactive blog. The collaboration group participants $(\mathrm{n}=21)$ met twice and provided valuable input for the development of a menu planning model, menu template, sample menus, recipes, and information sheets. The model unified the menu planning considerations and served as a framework for the Child Care Centre Menu Project website (http://www.msvu.ca/menuproject/). The follow-up evaluation indicated that approximately half of respondents $(n=39)$ had consulted the website and that the sample menus were the most useful resource. The website, blog, and online survey enable ongoing development supported by input from the menu planners. The resources should be transferable, with minor adaptations, to other provincial child care centres, elementary schools, or even licensed senior care facilities.

\section{Acknowledgments}

This project was funded by a Mount Saint Vincent University internal research grant and a Canadian Institutes of Health Research health professional student research award.

Approximately $25 \%$ of Canadian children and $30 \%$ of Nova Scotian children are overweight or obese, conditions that are known to negatively affect quality of life and life expectancy (Ascentum for Federal, Provincial, and Territorial Ministers of Health, 2011; Veugelers, Fitzgerald, \& Johnston, 2005). However, there is strong evidence that development of healthy eating behaviours, if established early in life, can be maintained through adulthood, promote healthy weight, and prevent certain chronic diseases (Ascentum for Federal, Provincial, and Territorial Ministers of Health, 2011; Briley, Jastrow, Vickers, \& Roberts-Gray, 1999; Briley, Roberts-Gray, \& Rowe, 1993; Drake, 1992; Gubbels et al., 2010; Nicklas et al., 2001; Nova Scotia Alliance for Healthy Eating and Physical Activity \& Office of Health Promotion, 2005; Pollard, Lewis, \& Miller, 1999; J. D. Skinner, Carruth, Bounds, Zeigler, \& Reidy, 2002).

On average, Canadian children spend 27 hours weekly in child care centres, and parents of those who attend full time rely on the centres to provide adequate foods to meet most of the daily dietary requirements and to teach the children about healthy eating behaviours (Lynch \& Batal, 2011; Dwyer, Needham, Simpson, \& Heeney, 2008; Moore et al., 2005). Further, as approximately $70 \%$ of Nova Scotian preschool children have mothers or both parents in the workforce (Bushnick, 2006), there is an opportunity for child care centres to play a key role in the development of healthy lifestyles.

Research studies over the past twenty years indicate, however, that nutrition standards of child care centre menus were not being met (Briley et al., 1993; Briley et al., 1999; Fleischhacker, Cason, \& 
Achterberg, 2006; McConahy, SmiciklasWright, Mitchell, \& Picciano, 2004; Nicklas et al., 2001; Romaine, Mann, Kienapple, \& Conrad, 2007). A pilot study comparing Head Start child care centres' menus with the actual food served found that, while $77 \%(\mathrm{n}=92)$ considered dietary guidelines in menu planning, only $14 \%$ provided adequate calories (Fleischhacker et al., 2006). Studies of portion sizes of foods provided to preschool-age children indicated that they were often over or under the recommended size, which may result in a diminished ability to regulate energy intakes later in life (Fox, Reidy, Karwe, \& Ziegler, 2006; McConahy et al., 2004). Specific to child care centres in Nova Scotia, it was determined that the legislative requirement for provision of one-third of daily nutrients was not being met, even though the existing guidelines for menu planning were followed (Romaine et al., 2007).

In 2007, stemming from an environmental scan of recent research (Nova Scotia Departments of Health Promotion \& Protection [now Health and Wellness] and Community Services, 2008) and recommendations of the Healthy Eating Nova Scotia report (Nova Scotia Alliance for Healthy Eating and Physical Activity, 2005), a provincial advisory group to "inform the development of a comprehensive food and nutrition policy for licensed child care in Nova Scotia" (Nova Scotia Departments of Health Promotion \& Protection and Community Services, 2008, p. 3) was formed. This led to the release of the standards, guidelines, and criteria in the Manual for Food and Nutrition in Regulated Child Care Settings (hereafter referred to as the Manual; Nova Scotia Departments of Community Services and Health Promotion \& Protection, 2011), as well as accompanying revisions to the Day Care Act (Province of Nova Scotia, 2011).

Good menu planning for child care centres, however, must consider and incorporate a number of factors that go beyond standards and guidelines that simply interpret nutritional and licensing requirements alone (Fleischhacker et al., 2006; Marotz, 2009; Romaine et al., 2007). To encourage the development of healthy eating behaviours in children, menus must plan for aesthetic appeal and the introduction of new foods (Marotz, 2009). Weekly menus should be consistent, or based on a pattern, and control for the frequency and intervals of occurrence of same, or similar, food items.

The menu is also the primary control for any food service operation, impacting its budget and image (Gregoire, 2010; Marotz, 2009). This is particularly applicable to child care centres that operate within tight budgetary restrictions and limited resources. A simplistic solution for child care centres could be for all to use a costed standard menu. However, this would negate the fact that menus are unique to the mix of ages, cultures, and backgrounds of a centre's children, as well as the centre's access to resources (Gregoire, 2010; Marotz, 2009). Costing also varies by region, season, and economic conditions (Romaine et al., 2007).

Despite the availability of menu planning guides and books, menu planners, whether they have completed training or not, struggle with balancing the multiple factors involved (Moore et al., 2005; Oakley, Bomba, Knight, \& Byrd, 1995). With the development and subsequent implementation of the Manual, the need for relevant and user-friendly menu planning resources that encompassed these multiple factors was identified (Nova Scotia Departments of Health Promotion \& Protection and Community Services, 2008). It was also evident that the child care centre menu planners must be engaged in the development of these resources to ensure the needs and expectations of the centres were incorporated and to allow centres to take ownership of the menu planning process.

Therefore, guided by an action research model to engage the child care centre menu planners, this study set out to identify current menu planning practices, determine the needs and expectations for menu planning resources, and develop relevant, user-friendly, and comprehensive menu planning resources that incorporate food and nutrition standards as well as other relevant factors.

\section{Method}

This study received approval from the Mount Saint Vincent University Research Ethics Board in 2010. It used an action research methodology with participants solicited from Nova Scotia regulated child care centres.

\section{Participants}

Regulated child care centres in Nova Scotia were identified from the Directory of Licensed Child Care Facilities (Nova Scotia Department of Community Services, 2010). Contact information was compiled for all 330 full-day centres, an e-mail distribution list was established, and messages were sent to invite centre menu planners to participate in the online questionnaire and/or to be a collaboration group participant. The criteria for participants were that they be involved in menu planning at their child care centre.

\section{Procedure}

The spiral technology action research (STAR) model (H. A. Skinner, Maley, \& Norman, 2006), illustrated in Figure 1, guided the procedure for this study. The STAR model combines technological design and community involvement in the continuous quality improvement process. The STAR model is based on the principles of action research, health promotion principles, behaviour change theories, and quality improvement and community mobilization practices to create a process that is centred on the user and "grounded in the everyday realities of the target population and organizations that work with the population" (H. A. Skinner et al., 2006, p. 408). 


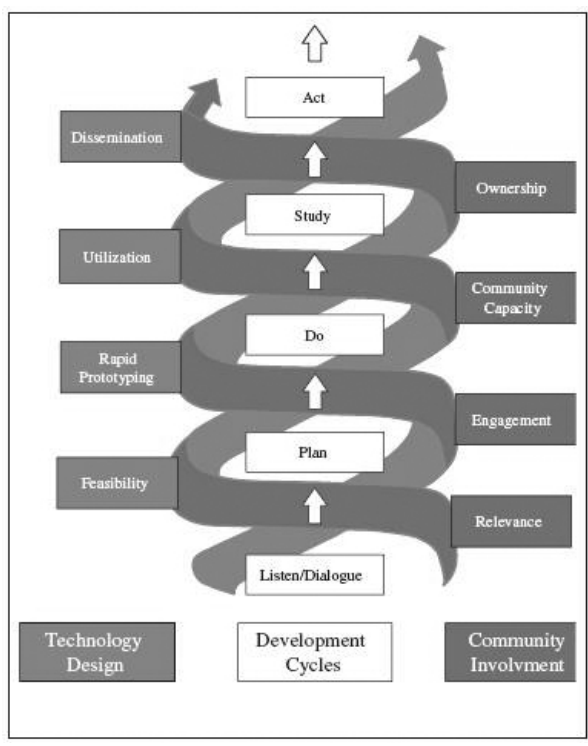

Figure 1. Spiral technology action research model (H. A. Skinner et al., 2006).

However, because this study required the incorporation of existing standards for food, nutrition, and menu planning, an additional step was added. The customerdriven management model (Leebov \& Ersoz, 1992), which is based on the principles of quality management, as first described by W. Edwards Deming (1986), informed the addition of this step as it incorporates community expectations as well as professional standards to create the menu planning resources. The listen-plan-do-study-act cycle, again first described by Deming (1986), provided an appropriate structure to allow for revisions to incorporate feedback throughout the study process.

Action research methodology was an important component of this research project. Menu planners were able to collaborate and state their menu planning needs, contributing to the development of resources which, in turn, was expected to lead to more control and confidence with the menu planning process (Baum, MacDougall, \& Smith, 2006; Wandersman \& Florin, 2003). By means of online questionnaires and collaboration group sessions, the researchers listened to the needs and expectations of the menu planners; ensured the standards were addressed; developed the appropriate resources; consulted, tested, and revised; and implemented the resources using the desired information technology. The following paragraphs outline the procedure (as suggested by the STAR model with the addition of a step named "standards."

\section{Standards}

Identification of the child care centre menu planning standards and best practices was an important step because it formed the foundation of the resources. At the time of this study, the Manual was still under development. However, the recommendations from the advisory group provided clear direction for the standards. Those that impacted menu planning included requirements for Canada's Food Guide (CFG; Health Canada, 2007) food group servings, recommendations for fluid milk to ensure a source of vitamin $\mathrm{D}$, and adherence to CFG best practices regarding food selection. To emphasize the latter recommendation and to limit use of processed foods, criteria for acceptable amounts of sodium, fat, refined sugar, and fibre were developed.

The advisory group also addressed the importance of introducing new foods in appealing ways to promote healthy eating behaviours. Sensory properties of food, such as colour, texture, shape, and flavour, enhance appeal and therefore acceptance (Marotz, 2009). For example, the sensory properties of a menu can be enhanced by having a contrast of at least two of the sensory properties and one item close to its natural form (baby carrots, berries, etc.). The recommendation for family style meal service was intended to allow children to make decisions about what and how much to eat in order to satisfy their hunger cues and establish independence (Marotz, 2009). These were all menu planning considerations as they impact the combination and preparation of foods.

Centres must also consider licensing regulations for administration and record keeping, such as advance posting of the menu and menu substitutions, food safety, budgets, and training requirements for menu planners as defined by the Day Care Act (Province of Nova Scotia, 2011).

These standards were summarized and subsequently compared to the results of the questionnaire and collaboration group discussions.

\section{Listen}

Information about menu planning current practices and the needs and expectations for resources was collected by an online questionnaire and collaboration group meetings. The online questionnaire sought responses about characterization of menus, menu planning processes and factors, experience and training, resources used, and expectations for new resources. Some questions were adapted from a previous study (Romaine et al., 2007) and others were based on the study objectives. The questionnaire was tested by three faculty members at the university and revised prior to distribution. The link to the questionnaire, which was posted online on SurveyMonkey ${ }^{\mathrm{TM}}$ (Palo Alto, CA 94301), was distributed by e-mail to all the regulated full day child care centres in Nova Scotia $(n=330)$. Reminder e-mails and phone calls were carried out to increase response rate.

The e-mail to the centres also included an invitation to participate in the collaboration group. The first collaboration group session $(n=21)$ utilized a World Café format (World Café, n.d.). Participants were randomly assigned to three discussion groups hosted by a researcher or research assistant. Each discussion group, sitting around a table covered with large sheets of paper, focused on specific topics for approximately 30 minutes, recording their ideas on the paper. The groups then each moved to another table to discuss another set of topics, and so on. The topics discussed at each table are outlined in Table 1.

Plan-Do-Study-Act

The plan-do-study cycle (see below for the "act" step) was repeated twice in the development of menu planning 
Table 1. World Café discussion group topics

\begin{tabular}{|c|c|c|}
\hline Group 1 & Group 2 & Group 3 \\
\hline $\begin{array}{l}\text { What do you think are characteristics } \\
\text { of a good menu? Are these realistic } \\
\text { to achieve? } \\
\text { How do you plan your menus? } \\
\text { Discuss similarities and differences. } \\
\text { What menu planning resources or } \\
\text { guides do you use? } \\
\text { What format do you prefer for these } \\
\text { resources or guides? Prompt by } \\
\text { saying checklist, flowchart, } \\
\text { framework, and model and available } \\
\text { online (website), on hard copy, or on } \\
\text { DVD? Other formats? }\end{array}$ & $\begin{array}{l}\text { How do you adjust your menus for } \\
\text { allergies and special diets? } \\
\text { Examples? } \\
\text { What resources do you refer to } \\
\text { about allergies and special diets? } \\
\text { What else would you like to have } \\
\text { available? } \\
\text { Show a sample weekly menu. How } \\
\text { would you modify it for child with } \\
\text { celiac disease (wheat allergy)? } \\
\text { What else would you need to } \\
\text { consider in feeding this child? }\end{array}$ & $\begin{array}{l}\text { Show a sample weekly menu. } \\
\text { Do you think it is a good menu? } \\
\text { Why or why not? } \\
\text { How would you improve this menu? } \\
\text { What resources would be helpful to } \\
\text { improve this menu? } \\
\text { Show a sample recipe. } \\
\text { The new menu standards will be } \\
\text { based on Canada's Food Guide food } \\
\text { groups. For a child-sized serving of } \\
\text { this recipe, can you identify the } \\
\text { number(s) of food group servings? } \\
\text { Can you identify how many food } \\
\text { guide servings are in this recipe? }\end{array}$ \\
\hline
\end{tabular}

resources that incorporated the food and nutrition standards, the information from the participants, and how they should be displayed using the chosen technology platform (website).

In the first cycle, the researchers compiled and analyzed the responses from the questionnaire and the World Café discussions. Descriptive statistics were used for the questionnaire and simple groupings of responses were used for the discussions. Based on these analyses and the identified standards, the researchers proceeded through a series of prototypes of the menu planning resources before presenting drafts for review by the collaboration group. The researchers also explored website options for distributing the resources.

A second collaboration group $(\mathrm{n}=17)$ meeting was then held to review the prototype resources. Again, using the World Café format and in three groups, participants were asked to critique and test the application of the resources. Next, the researchers revised and developed additional resources and distributed them for feedback. A second questionnaire was developed using SurveyMonkeyTM and distributed by e-mail to the same group of Nova Scotia child care centres. The questions elicited feedback from respondents about which resources had been accessed and which were most useful, as well as any suggestions for ongoing improvements.
The "act" step is the ongoing maintenance of the website and its resources, including means used for evaluation and feedback from users.

\section{Results and Discussion}

\section{Participants}

The response rate for the initial online questionnaire was 83 or $25 \% \quad(n=330)$. All efforts were made to ensure the e-mail addresses were accurate; the research assistant phoned those who had e-mails undelivered. An option to respond to the questionnaire by phone was also offered, but no one chose that option. There was representation from centres with varying licensing capacities, ranging from $10-$ 25 to greater than 101 children, with a median of 26-50; half were from the main urban centre and half from all across the province. By comparison, a previous study (Romaine et al., 2007) using a mailed survey to a random sample based on provincial distribution to 101 centres had 35 responses. Therefore, it may be suggested that the technology that now allows for electronic surveys played a role in the larger response. It is also expected that the pending release of the Manual (Nova Scotia Departments of Community Services and Health Promotion \& Protection, 2011) increased interest in this study about menu planning.

Fifty-five percent of respondents indicated that they were directors or owners of the centres, $20 \%$ were caregivers, $16 \%$ had multiple roles, and only $9 \%$ were cooks. It had been expected that cooks would have been the menu planners more so than the others; however, $46 \%$ of respondents indicated that they consult with their cooks when developing and implementing a menu. In smaller centres there is less likelihood of having dedicated cooks as centre staff likely participate in menu planning and preparation as part of a general, multitasking role.

While 25 child care centre menu planners initially consented to be members of the collaboration group, only 15 attended the first session and 17 the second. While the majority were from the main urban centre, there was representation from rural areas. The information from the first World Café was made available on SurveyMonkey ${ }^{\mathrm{TM}}$ and the link was distributed by e-mail to all who had consented to be members of the collaboration groups. This allowed those who couldn't attend to contribute and, for those who were present, to contribute further; six participants responded.

\section{Current Menu Planning Practices}

When questionnaire respondents were asked to characterize their menus, the top four responses were nutritious (94\%), meets government policies $(71 \%)$, kid friendly $(43 \%)$, and practical (41\%). Less frequently selected responses included cost effective (23\%), adaptable to special diet needs $(27 \%)$, creative $(7 \%)$, and environmentally sensitive $(6 \%)$. Most $(87 \%)$ were satisfied with the characterization of their menus but indicated an interest in addressing the less frequently selected areas.

While $60 \%$ of respondents reported that they revised their menus at least yearly, $40 \%$ had not revised their menus for a year or more. Reasons for this, gathered from the collaboration discussions, included uncertainty with government policies and guidelines as well as lack of time. Regular menu revisions ensure incorporation of the specific needs of the children, current eating trends, seasonal adaptations, and changing centre resources. 
Menu planning was reported as a collaborative process for the questionnaire respondents. Centre staff $(71 \%)$, cooks $(46 \%)$, children $(24 \%)$, parents $(15 \%)$, and, externally, public health nutritionists (69\%) and childhood development officers $(19 \%)$ all provided input into menus. While parents were the least consulted, they have a large influence on the development of healthy eating behaviours and, as such, there are many unexplored opportunities for engagement (American Dietetic Association, 2005; Gibbons, Graham, Marraffa, \& Henry, 2000).

When asked to identify factors considered in menu planning, respondents identified CFG (75\%), cost effectiveness (71\%), specific nutrients in foods (71\%), government policies/guidelines (68\%), ease of preparation (60\%), child preferences $(53 \%)$, allergies/special diets $(53 \%)$, and local/seasonal foods $(47 \%)$ most often. Less often selected factors included food availability (35\%), sensory appeal of foods (30\%), kitchen equipment $(18 \%)$, cultural needs $(15 \%)$, and personal preferences $(1 \%)$. These numbers illustrate that menu planners have a complex array of factors to address (Fleischhacker et al., 2006; Romaine et al., 2007).

\section{Needs and Expectations for Menu \\ Planning Resources}

Resources most often used for menu planning were CFG (89\%), menus from other centres $(52 \%)$, and nutrition or menu planning books (40\%). Respondents expressed a need for sample menus, menu templates, and recipes, with associated costs. Almost equal numbers of respondents indicated that they would like to have these menu planning resources provided on a website $(66 \%)$ and in hard copy $(62 \%)$, similar to other reports (Burden, Sheeshka, Hedley, Lero, \& Marsh, 2000; O'Mara \& Chambers, 1992; Romaine et al., 2007). Thirty-six percent indicated that they would like to have an interactive website or blog for consulting with other child care centres' menu planners and/or experts. Most $(92 \%)$ reported that they had access to a computer for menu planning.

When asked about other information resources, respondents indicated they wanted to learn more about creative menu planning (79\%), recipe and menu costing (65\%), allergies/special diets (59\%), nutrition $(56 \%)$, and how to introduce new foods to children (54\%). These results are similar to those in other reports (Gibbons et al., 2000; Romaine et al., 2007).

The collaboration group participants responded well to the World Café approach. Table 2 summarizes the types of responses gathered from the first collaboration group, including the followup questionnaire. See Table 2 (next page) To initiate discussion among the collaboration group participants, they were asked to share their suggestions for menu items and recipe modifications that would meet the new standards. Some of these creative ideas were to add red lentils to tomato soup to provide both a meat alternate serving and a vegetable serving for a noon meal, serving "deconstructed" casseroles such as chicken cacciatore with the ingredients separated to make the menu item more appealing to children who are reluctant to accept combinations, and replacing the ground beef in spaghetti sauce with tofu to make the menu item suitable for vegetarians. Interestingly, the collaboration group participants were not supportive of "hiding" vegetables in menu items, although they did indicate that they would add extra vegetables to soups and sauces, for example.

\section{Development of Resources}

Based on the review of the standards and analyses of the questionnaire and collaboration group discussions, the researchers grouped the menu planning standards and considerations under four main sections to form a menu plan model (see Figure 2). It was felt that the pictorial representation would assist menu planners to organize and prioritize the various disparate factors. An explanation of the model was also prepared.

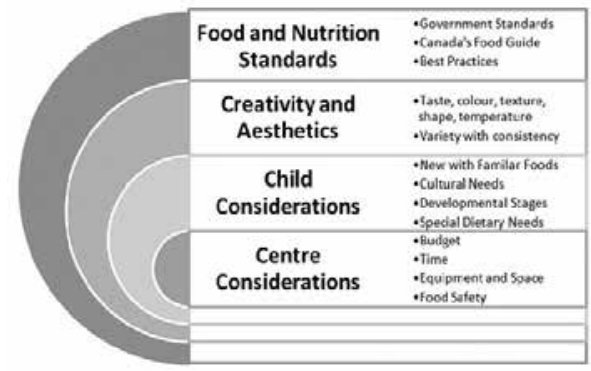

Figure 2. Child care centre menu plan model.

To unify the resources, the headings and colours of the model were used for the evaluation form and the resource list; they were also later used for the website design. A menu template that incorporated the proposed standards and repetition control was designed, as was a sample menu. The sample menu included a description of how the standards and considerations were applied, thus building capacity for menu planning and evaluation. A guide for calculating food group servings from recipes was identified. The task of costing recipes and calculating their food group servings was initiated.

These draft resources were presented to the participants at the second collaboration group session. Feedback about the resources was recorded as they tested the utility of the template and evaluation for menu planning. Participants were able to design and evaluate menus using the resources, and they appreciated the opportunity to brainstorm with other menu planners. In a general group discussion, participants suggested that video(s), available on the website, would enhance communication and understanding of how to apply the model.

Following the second collaboration group session, the resources were adjusted based on participant feedback and experience. Additional sample menus were developed based on the ones created during the collaboration group session. The costs and food group servings for a selection of recipes were calculated, and a link to allow menu planners to submit recipes for 
Table 2. World Café discussion group responses: Collaboration Group $1(\mathrm{n}=\mathbf{2 1})$.*

\begin{tabular}{|c|c|}
\hline Discussion Group Topics & Responses \\
\hline \multirow[b]{3}{*}{$\begin{array}{l}\text { What are the characteristics of a good menu? Do } \\
\text { you think it is realistic to achieve these and why? }\end{array}$} & $\begin{array}{l}\text { "Menu item variety, challenging, sensory variety, lots of food } \\
\text { choices, balancing it with Canada's Food Guide." }\end{array}$ \\
\hline & $\begin{array}{l}\text { "Cost effective, kid friendly, incorporating seasonal foods, } \\
\text { appropriate portion sizes, offering choice, de-emphasizing } \\
\text { desserts, flexibility." }\end{array}$ \\
\hline & $\begin{array}{l}\text { "Yes, it can be realistic to achieve these but it could become too } \\
\text { expensive to buy what you want. It is more difficult for the } \\
\text { larger centres with so many individual food preferences. It is } \\
\text { difficult to control the plate presentation with family-style meal } \\
\text { service. Having flexibility can be challenging with the } \\
\text { regulations and standards in place. Child care centres need to } \\
\text { continue trying new things and offering foods more than once- } \\
\text { even if the children do not like it the first time." }\end{array}$ \\
\hline \multirow{7}{*}{$\begin{array}{l}\text { How do you plan your menus? Do you use tools or } \\
\text { checklists? How do you manage the process? }\end{array}$} & $\begin{array}{l}\text { "I plan based on what is on sale in the store. I mentally plan for } \\
\text { one vegetarian, one poultry, one beef, one pork, and one fish per } \\
\text { week." }\end{array}$ \\
\hline & $\begin{array}{l}\text { "I consider the age of the children, I use the checklists we are } \\
\text { given from the nutritionist, and I closely watch what the children } \\
\text { like and dislike. I try to incorporate the foods that they dislike } \\
\text { into the menu in a variety of ways." }\end{array}$ \\
\hline & $\begin{array}{l}\text { "We use things that have worked in the past. We try out new } \\
\text { ideas to see how well they work. We look on the internet and ask } \\
\text { parents for recipes. It is frustrating to come up with enough } \\
\text { variety for snacks." }\end{array}$ \\
\hline & "Consultation with other centres." \\
\hline & "Keep a record of old menus to draw ideas." \\
\hline & "Consult with public health nutritionist for menu ideas." \\
\hline & $\begin{array}{l}\text { "Check government regulations to see if a new item meets } \\
\text { requirements." }\end{array}$ \\
\hline \multirow{4}{*}{$\begin{array}{l}\text { What format do you prefer for resources? Do you } \\
\text { prefer a model, a checklist, examples, etc? }\end{array}$} & "Anything concrete helps!" \\
\hline & $\begin{array}{l}\text { "I learn through hands-on approaches. I like checklists and } \\
\text { models." }\end{array}$ \\
\hline & $\begin{array}{l}\text { "I would learn the menu planning process best if there was a } \\
\text { dedicated website for child care centre menu planning." }\end{array}$ \\
\hline & $\begin{array}{l}\text { "I would like a bank of recipes, a way to communicate with } \\
\text { other centres, and costed recipes." }\end{array}$ \\
\hline
\end{tabular}

Includes responses to follow-up questionnaire.

costing was established. An instructional video to provide commentary to guide site users through the menu planning process and use of the resources was produced. The website (Child Care Centre Menu Project, 2010) was established on the Mount Saint Vincent University server. A WordPress blog was created and linked to the website. Finally, the website went live, and regulated full-day child care centres in Nova Scotia were notified. The blog and the recipe costing feature addressed the community involvement ownership component as outlined in the STAR model (H. A. Skinner et al., 2006).

Six weeks after the website went live, an evaluation questionnaire was distributed to the Nova Scotia child care centres. The response rate was 48 or $14.5 \%(n=330)$. Fifty percent had accessed the website and of this group, $83 \%$ had viewed the sample menus, $67 \%$ the menu plan model, $50 \%$ the child food group best practices, and $50 \%$ the recipes. Eighty-five percent of the respondents indicated that they plan to use the website resources in the future. No one had used the blog even though $40 \%$ had requested it be included on the site. It may be that menu planners are interested in the potential of this technology, but without prior experience, are reluctant to be an early user.

\section{Conclusion}

Menu planning resources, such as the ones developed by this study, was a need identified by Nova Scotia child care centres in the Food and Nutrition Support Environmental Scan (Nova Scotia Departments of Health Promotion
$\&$ Protection and Community Services, 2008) and again in the public consultations (Nova Scotia Departments of Community Services and Health Promotion \& Protection, 2010) prior to the release of the Manual (Nova Scotia Departments of Community Services and Health Promotion \& Protection, 2011).

Minor revisions were made to the website resources, in particular the model, child food group best practices, menu template, and sample menus, so that they coincided with the final content of the Manual. The website resources have proven to be valuable aids for students in the nutrition and child study programs at Mount Saint Vincent University; this was an unanticipated but welcome outcome. As predicted, maintaining and updating the recipes with costs has proven to be difficult. Future revision of the website, including a planned migration to the WordPress blog, will involve removal of the costed recipes and replacement with links to recipe sites.

The STAR model, with the addition of the step to identify standards, was well suited for this study. Utilizing this action research approach resulted in an eHealth promotion outcome (H. A. Skinner et al., 2006): the Child Care Centre Menu Project website. The principles of action research enabled the researchers to build a trusting relationship with the collaboration group and therefore ensured that the needs and expectations of the menu planners were incorporated in the website resources. In turn, it is expected that incorporating the menu planners' needs will give them confidence in their ability to plan menus that will appeal to young children, that will meet the food and nutrition standards, and that will be unique to the specific character of their centres. As one participant stated, "menus must be specific to the particular centre and its children; there can't be one menu that fits all."

The Child Care Centre Menu Project website and its resources should be relevant and adaptable to child care centres in other provinces, elementary 
schools, and, potentially, licensed senior care facilities.

\section{References}

American Dietetic Association. (2005). Position of the American Dietetic Association: Benchmarks for nutrition programs in child care settings. Journal of the American Dietetic Association, 105(6), 979-986.

Ascentum for Federal, Provincial, and Territorial Ministers of Health. (2011). Our health our future: A national dialogue on healthy weights. Ottawa, ON: Public Health Agency of Canada. Retrieved from: http://www. phac-aspc.gc.ca/hp-ps/hl-mvs/ohof-nsna/index-eng. php

Baum, F., MacDougall, C. \& Smith, D. (2006). Participatory action research. Journal of Epidemiology \& Community Health, 60(10), 854-857.

Briley, M. E., Jastrow, S., Vickers, J., \& Roberts-Gray, C. (1999). Dietary intake at child-care centers and away: Are parents and child care providers working as partners or at cross-purposes? Journal of the American Dietetic Association, 99, 950-954.

Briley, M. E., Roberts-Gray, C., \& Rowe, S. (1993). What can children learn from the menu at the child care center? Journal of Community Health, 18, 363-377.

Burden, T., Sheeshka, J., Hedley, M., Lero, D. S., \& Marsh, S. (2000). Development, implementation, and evaluation of a nutrition education program for informal (unlicensed) child caregivers. Journal of Nutrition Education, 32, 104-110.

Bushnick, T. (2006). Child care in Canada. Ottawa, ON Statistics Canada. Retrieved from: http://www.statcan gc.ca/pub/89-599-m/89-599-m2006003-eng.htm

Child Care Centre Menu Project. (2010). Retrieved from: http://www.msvu.ca/menuproject/

Deming, W. E. (1986). Out of crisis. Cambridge, MA: Massachusetts Institute of Technology, Centre for Advanced Engineering Study.

Drake, M. A. (1992). Menu evaluation, nutrient intake of young children, and nutrition knowledge of menu planners in child care centers in Missouri. Journal of Nutrition Education, 24, 145-148.

Dwyer, J., Needham, L., Simpson, J. R., \& Heeney, E. S (2008). Parents report intrapersonal, interpersonal, and environmental barriers to supporting healthy eating and physical activity among their preschoolers. Applied Physiology, Nutrition, and Metabolism, 33(2) 338-346.

Fleischhacker, S., Cason, K. L., \& Achterberg, C. (2006). You had peas today: A pilot study comparing a Head Start child care center's menu with the actual food served. Journal of the American Dietetic Association, 106(2), 277-280.

Fox, M. K., Reidy, K., Karwe, V., \& Ziegler, P. (2006). Average portions of foods commonly eaten by infants and toddlers in the United States. Journal of the American Dietetic Association, 106(1), 66-76.
Gibbons, K., Graham, V., Marraffa, C., \& Henry, L. (2000) "Filling the gap": Children aged between two and four years: Sources of nutrition information used by families and child care staff. Australian Journal of Nutrition and Dietetics, 57(4), 208-214.

Gregoire, M. B. (2010). Foodservice organizations: A managerial and systems approach (7th ed.). Newmarket, ON: Pearson Education Canada.

Gubbels, J. S., Kremers, S. P. J., Stafleu, A., Dagnelie, P. C., de Vries, N. K., van Burren, S., \& Thijs, C. (2010) Child-care use and the association with body mass index and overweight in children from 7 months to 2 years of age. International Journal of Obesity, 34, $1480-1486$.

Health Canada. (2007). Eating well with Canada's food guide. Ottawa, ON: Author. Retrieved from: http:// www.hc-sc.gc.ca/fn-an/food-guide-aliment/index-eng. php

Leebov, W., \& Ersoz, C. J. (1992). The health care manager's guide to continuous quality improvement. Chicago, IL: American Hospital Publishing.

Lynch, M., \& Batal, M. (2011). Factors influencing child care providers' food and mealtime decisions: An ecological approach. Child Care in Practice, 17(2), 185-203.

Marotz, L. R. (2009). Health, safety and nutrition for the young child (7th ed.) Clifton Park, NY: Thomson Delmar Learning.

McConahy, K. L., Smiciklas-Wright, H., Mitchell, D. C., \& Picciano, M. F. (2004). Portion size of common foods predicts energy intake among preschool aged children. Journal of the American Dietetic Association, 104(6), 975-979.

Moore, H., Nelson, P., Marshall, J., Cooper, M., Zambas, H., Brewster, K., \& Atkin, K. (2005). Laying foundations for health: Food provision for under- $5 \mathrm{~s}$ in day care. Appetite, 44(2), 407-413.

Nicklas, T. A., Baranowski, T., Baranowski, J. C., et al (2001). Family and child-care provider influences on preschool children's fruit, juice, and vegetable consumption. Nutrition Reviews, 59(7), 224-235.

Nova Scotia Alliance for Healthy Eating and Physical Activity in partnership with Office of Health Promotion. (2005). Healthy eating Nova Scotia. Halifax, NS: Author. Retrieved from: http://www.gov. ns.ca/ohp/healthyEating.html

Nova Scotia Department of Community Services. (2010). Directory of licensed child care facilities. Halifax, NS Author. Retrieved from: http://www.gov.ns.ca/coms/ families/child care/directories/SearchResults.aspx

Nova Scotia Departments of Community Services and Health Promotion \& Protection. (2010). Food and nutrition support policy for regulated child care settings: Consultation results. Halifax, NS: Author.

Nova Scotia Departments of Community Services and Health Promotion \& Protection. (2011). Manual for food and nutrition in regulated child care settings. Halifax, NS: Author. Retrieved from: http://www. gov.ns.ca/coms/families/provider/documents/ManualFood_and_Nutrition.pdf
Nova Scotia Departments of Health Promotion \& Protection and Community Services. (2008). Food and nutrition support in licensed child care centres in Nova Scotia: Environmental scan and literature review. Halifax, NS: Author. Retrieved from: http://www. gov.ns.ca/hpp/publications/FNSLCCF Executive Summary_FINAL.pdf

Oakley, C. B., Bomba, A. K., Knight, K. B., \& Byrd, S H. (1995, January 1). Evaluation of menus planned in Mississippi child-care centers participating in the Child and Adult Care Food Program. Journal of the American Dietetic Association, 95(7), 765-768.

O'Mara, L. M., \& Chambers, L. W. (1992). How can local health agencies improve health knowledge and skills of child care centre operators? Canadian Journal of Public Health, 83, 208-212.

Pollard, C. M., Lewis, J. M., \& Miller, M. R. (1999). Food service in long-day care centres: An opportunity for public health intervention. Australian and New Zealand Journal of Public Health, 23(6), 606-610.

Province of Nova Scotia. (2011). Day care regulations under section 15 of the Day Care Act. Halifax, NS: Author. Retrieved from: http:/www.gov.ns.ca/just regulations/regs/dayregs.htm

Romaine, N., Mann, L., Kienapple, K., \& Conrad, B. (2007). Menu planning for child care centres: Practices and needs. Canadian Journal of Dietetic Practice and Research, 68, 7-13.

Skinner, H.A., Maley, O., \& Norman, C. D. (2006) Developing internet-based e-health promotion programs: The spiral technology action research (STAR) model. Health Promotion Practice, 7(4), 406-417.

Skinner, J. D., Carruth, B. R., Bounds, W., Zeigler, P., \& Reidy, K. (2002). Do food related experiences in the first years of life predict dietary variety in school age children? Journal of Nutrition Education Behavior, 34 , $310-315$.

Veugelers, P. J., Fitzgerald, A. L., \& Johnston, E. (2005). Dietary intake and risk factors for poor diet quality among children in Nova Scotia. Canadian Journal of Public Health, 96(3), 212-216.

Wandersman, A., \& Florin, P. (2003). Community interventions and effective prevention. American Psychologist, 58(6-7), 441-448.

World Café. (n.d.). World Café method. Retrieved from: http://www.theworldCafé.com/method.htm 